\title{
Avaliação da Interação de Crianças em Pátios de Escolas Infantis: Uma Abordagem da Psicologia Ambiental
}

\author{
Fabio Sager ${ }^{12}$ \\ Tania Mara Sperb \\ Universidade Federal do Rio Grande do Sul \\ Antonio Roazzi \\ Universidade Federal de Pernambuco \\ Fernanda Marques Martins \\ Universidade Federal do Rio Grande do Sul
}

\begin{abstract}
Resumo
O estudo dos aspectos físico-espaciais dos ambientes e suas relações com a subjetividade e o comportamento humanos têm sido cada vez mais investigados pela psicologia. Assim, este estudo investigou a relação entre os pátios de duas escolas infantis municipais de Porto Alegre e a interação de 50 crianças de 5 a 6 anos que frequentavam a escola. Estas foram observadas nos pátios das escolas, os quais apresentavam diferenças em termos de área, densidade de crianças e materiais. Foram observados os tipos de brincadeiras e brinquedos utilizados pelas crianças e os tipos de interações estabelecidos entre elas. Os resultados, provenientes de análises quantitativas, mostraram que as crianças estabeleceram mais interações associativas e paralelas no pátio grande e mais do tipo desocupada e solitária no pátio pequeno. Quanto ao tipo de brinquedo, no pátio grande a associação desse aspecto com os tipos de interação foi menor do que no pátio pequeno. Houve maior associação entre as interações e os tipos de brincadeiras no pátio pequeno. Concluiu-se que, com relação aos aspectos ambientais, o pátio grande favorece uma maior variação de interações. Palavras-chave: Psicologia ambiental; interações infantis; escola infantil.
\end{abstract}

The Evaluation of Preschoolers' Interaction in the Playground: An Environmental Psychology Approach

\begin{abstract}
The physical-spatial aspects of environments and their relation to subjectivity and human behavior have been increasingly studied by psychologists. Thus, this study investigated the relationship between playgrounds of two public preschools of Porto Alegre and the interaction of 505 to 6 year-old children who were enrolled in these schools. Children were observed at the playgrounds, which presented differences in terms of area (size), density and materials. The interaction states observed were related to types of play and toys used. Results drawn from quantitative analyses showed that children established more associative and parallel interaction states in the large playground, and unoccupied and solitary in the small playground. As for the type of toy, the association of this aspect with the interaction in the large playground was smaller than in the small one. A higher association between interactions and types of play in the small playground was found. The study shows that concerning environmental aspects the large playground favors a variety of interactions states.

Keywords: Environmental psychology; child interaction; preschool.
\end{abstract}

De alguma forma, a maioria dos autores clássicos da Psicologia deparou-se com a questão da relação entre organismo e ambiente, ou do homem e as influências do contexto em que vive (Barker, 1965; Lewin, 1951).

A Psicologia Ambiental é uma vasta área no grande espectro das teorias psicológicas contemporâneas e cujo ponto principal sempre foi o estudo das influências ambientais na subjetividade e no comportamento humanos.

\footnotetext{
${ }^{1}$ Notas e agradecimentos: este artigo é resultado da disciplina Teorias em Desenvolvimento Psicológico II do Pós-Graduação em Psicologia do Desenvolvimento - UFRGS. Agradecemos o apoio financeiro do CNPq. ${ }^{2}$ Endereço para correspondência: Curso de Pós-Graduação em Psicologia, UFRGS, Rua Ramiro Barcelos, 2600/116, 90035 003. Porto Alegre, RS. E-mail: fsager@terra.com.br
}

Um foco de trabalho importante dentro do campo da Psicologia Ambiental é o estudo do modo pelo qual as pessoas utilizam o espaço como meio de regular suas interações. Um dos aspectos estudados nessa área diz respeito ao impacto de características físicas do ambiente nas relações interpessoais.

Da mesma maneira, a interação das crianças com os contextos onde elas atuam e o modo como esses contextos afetam suas interações é, hoje, fonte de interesse para muitos investigadores. Uma série de autores tem pesquisado a importância do ambiente fisico e dos materiais para o desenvolvimento das relações infantis, bem como para os estilos das brincadeiras e para o uso de objetos (Civilletti, 1992; Ladd \& Coleman, 1992; Sager, 1996; Vanderberg, 1981).

Uma idéia partilhada por alguns desses autores é a de que o contexto no qual as crianças brincam determina a 
maneira como elas interagem entre si. Visto que a escola consiste no ambiente por excelência da criança, pois é nela que as crianças passam importantes momentos de suas vidas e desenvolvem as suas primeiras habilidades sociais e intelectuais, o ambiente escolar costuma ser o principal foco de estudo dessas investigações.

Alguns trabalhos (Civilletti, 1992; Legendre, 1995; Neil \& Denham, 1982; Sager, 1996) evidenciam, por exemplo, que o desenho das salas, dos pátios e a provisão de materiais estão fortemente relacionados à qualidade das relações que ocorrem entre as crianças.

Civilletti (1992), em um estudo abordando o tamanho dos brinquedos e sua influência na autonomia das crianças, verificou que quando as crianças utilizavam brinquedos de grandes dimensões, sua autonomia, em relação aos adultos que delas cuidavam, aumentava.

Sager (1996), por sua vez, procurou relacionar os padrões de conflitos nas interações de crianças da escola infantil com o ambiente físico e o gênero, bem como com os tipos de materiais e brinquedos envolvidos nas relações dessas crianças. Os resultados mostraram diferenças nos padrões de conflito em relação aos dois contextos estudados - sala e pátio - e em relação aos tipos de brincadeiras. No contexto sala, os conflitos estavam relacionados, principalmente, a brincadeiras que envolviam atividade simbólica (cf. classificação de Parten, 1932). Já o brincar em atividades de exercício mostrou estar relacionado a conflitos quando o contexto era o pátio.

Outro fator do ambiente físico que influencia as interações das crianças diz respeito à disponibilidade ou quantidade de brinquedos (Ladd \& Coleman, 1992). Smith e Connolly (1980), por exemplo, examinaram o brincar entre crianças, relacionando-o à quantidade de brinquedos disponíveis. Eles verificaram que quanto menor era a disponibilidade de brinquedos, mais as crianças tendiam a brigar e a engajar-se em atividades paralelas. Por outro lado, as crianças procuravam brincar sozinhas quanto maior era a quantidade de brinquedos disponíveis.

Tão importante quanto a disponibilidade de brinquedos é o tipo de equipamento que envolve as interações entre crianças. Smith (1974, citado em Ladd \& Coleman, 1992) examinou os efeitos de atividades motoras finas e amplas nas interações entre as crianças. Smith observou a brincadeira de crianças em três contextos diferentes: o primeiro, incluía um grande aparato, por exemplo, uma casa de brincar; o segundo, incluía um pequeno brinquedo, como um quebracabeças ou uma boneca, e o terceiro configurava uma condição-controle que incluía, simultaneamente, um brinquedo grande e um pequeno. No caso da condição com grandes aparatos, houve significativo aumento nas interações e, surpreendentemente, um aumento no nível do brincar cooperativo em crianças que, anteriormente, brincavam sozinhas ou paralelamente. Ao contrário, o comportamento desocupado e o brincar orientado por adultos mostraram-se mais comuns em condições em que o aparato era constituído de brinquedos pequenos.

Vanderberg (1981), igualmente, comparou o brincar de crianças de escola infantil em ambientes providos de aparelhos que promoviam atividades motoras amplas com ambientes onde os brinquedos estimulavam atividades motoras finas, como aqueles desenvolvidos com papel, tesouras e lápis. Os resultados evidenciaram que as interações eram mais comuns naqueles ambientes onde os equipamentos propiciavam atividades motoras amplas.

Um outro aspecto do ambiente físico que vem mostrando ser importante para as interações infantis é o arranjo espacial. Legendre (1995), por exemplo, vem se dedicando ao estudo do papel dos arranjos espaciais enquanto suporte para as interações infantis. Em um de seus estudos, ele investigou a influência de zonas circunscritas (áreas localizadas em cantos, delimitadas em pelo menos três lados por barreiras formadas por mobiliário, paredes, diferenças no nível do solo, etc) nas interações infantis. Foram considerados três tipos diferentes de arranjos espaciais, ou seja, semi-aberto, aberto e fechado. Os resultados mostraram que, em arranjos espaciais abertos, as crianças preferiram brincar em áreas próximas ao educador, em contraste com arranjos semi-abertos. As zonas circunscritas mostraram-se as mais atrativas, sendo preferencialmente utilizadas pelas crianças.

No Brasil, Campos de Carvalho e Rossetti-Ferreira (1993) conduziram um estudo semelhante. Elas modificaram o arranjo espacial de duas pré-escolas, no intuito de investigar o papel do arranjo espacial enquanto suporte para as interações infantis. Assim como Legendre (1995), as autoras verificaram que as crianças mostraram uma clara preferência pelas zonas circunscritas. Nesses locais, segundo as autoras, as crianças podem permanecer em pequenos grupos, participando de atividades sem a necessidade da mediação de um adulto e sem interrupções freqüentes de outras crianças, o que poderia explicar sua preferência por essas áreas. Além disso, essas zonas seriam preferidas por propiciarem uma sensação de proteção e privacidade, permitindo que as crianças se concentrassem em suas atividades e no comportamento de seus pares. As zonas circunscritas, então, atuariam como suporte para o estabelecimento e a manutenção das interações infantis.

A influência da definição espacial do ambiente no comportamento de crianças foi igualmente estudada por Moore (1986). Em seu trabalho, o nível de definição espacial se mostrou preditor de uma série de comportamentos das crianças. Em ambientes bem definidos ocorreram mais comportamentos exploratórios, interações sociais e 
cooperação do que em ambientes parcialmente ou pouco definidos espacialmente.

Contextos abertos, como pátios e parques, são igualmente importantes em termos de interações entre crianças. Segundo Frost (1989), nesses ambientes as brincadeiras sociais são muito mais freqüentes do que em ambientes fechados, o que pode beneficiar bem mais algumas crianças.

Há estudos que comparam diferentes estilos de ambientes abertos com diferentes comportamentos de interação. Um estudo que aborda o tipo de interação relacionado a aspectos físicos de espaços abertos é o de Campbell e Frost (1985). Segundo os autores, os pátios podem ser classificados em quatro tipos: tradicional (superfície plana, com escorregador, balanços, etc.); projetados (com estruturas feitas em madeira, pedras de vários níveis); Aventura (espaço com materiais para que as crianças construam suas próprias estruturas) e criativo (uma combinação de projetado e aventura). Os autores verificaram que as crianças apresentaram mais interações do tipo paralela em pátios tradicionais, enquanto que no pátio criativo a maioria das interações foi do tipo solitária. As interações cooperativas não variaram com relação ao tipo de pátio. Um estudo semelhante foi conduzido por Hart e Sheenan (1986) no qual compararam o brincar entre companheiros em ambientes tradicional e projetado. Apesar de as diferenças não terem sido significativas, eles observaram altos níveis de comportamento desocupado e solitário no ambiente projetado, em oposição ao ambiente tradicional.

A densidade de crianças nos espaços e as áreas disponíveis para brincar também são fatores relevantes quando se quer relacionar aspectos do ambiente e a interação de crianças. A falta de espaço em contextos escolares acarreta uma série de problemas. Em relação a isto, Hart e Sheenan (1986) afirmam que

espaços, tempo e oportunidades limitados oferecidos às crianças nos períodos de intervalo diminuem as possibilidades de interação entre elas e o ambiente que as cerca. Isso as leva à correria, conflitos, amontoado de alunos em certas áreas, apropriação dos melhores espaços pelas crianças mais velhas e disputas. (p. 26)

De um modo geral, os estudos têm verificado que um aumento na densidade de crianças nas salas e pátios aumenta substancialmente a quantidade de conflitos e agressões. Campbell e Dill (1985), por exemplo, observaram, em entrevistas realizadas com professores, que o aumento na densidade de crianças nas salas gerava um aumento de problemas nas relações entre essas crianças. Nesses ambientes, essas relações se tornavam angustiantes e conduziam a altos níveis de irritação e frustração. Já Smith e Connolly (1980), ao monitorarem o comportamento de crianças em três ambientes de densidades diferentes, mostraram que grupos de brincadeiras foram menos comuns em ambientes de alta densidade. Crianças colocadas em ambientes de densidades superiores a $1 \mathrm{~m}^{2}$ por criança tiveram uma diminuição no número de interações e de afetos positivos, com concomitante aumento dos níveis de agressão. Segundo Frost, Shin e Jacobs (1998), os estudos sobre o efeito da alta densidade nas interações das crianças sugerem que altos níveis de densidade social apresentam efeitos negativos nas crianças.

Liempd (1999), por sua vez, investigou diversos pátios escolares e verificou que a medida recomendada de 4 metros quadrados por criança era insuficiente em termos da qualidade desses ambientes para as crianças. Segundo ele, os pátios com menos de 6 metros quadrados por criança não funcionavam bem, pois eram muito densos. Nestes pátios menores, as crianças não podiam brincar quando queriam. Era preciso que se organizasse o uso do pátio em termos de rodízio de grupos de crianças. Além disso, nesses ambientes, certos tipos de brincadeiras eram proibidos, não por serem perigosos, mas pela falta de espaço, que ocasionava o risco de colisão entre as crianças.

No outro extremo, áreas grandes demais, com pouca densidade de crianças, também apresentam aspectos negativos. Moore (1986), ao estudar jardins de infância para crianças de 2 a 5 anos, afirma que espaços muito grandes podem levar ao barulho e à confusão, passando a ser subutilizados. Ele criou a seguinte recomendação de tamanho de pátios (em $\mathrm{m}^{2} /$ criança):

\begin{tabular}{llll} 
Pátios & Mínimo & Recomendado & Generoso \\
\hline Densidade $(\mathrm{m} 2 / \mathrm{cr})$. & $7,5 \mathrm{~m} 2 / \mathrm{cr}$ & $10 \mathrm{~m} 2 / \mathrm{cr}$ & $20 \mathrm{~m} 2 / \mathrm{cr}$
\end{tabular}

Neste sentido, Fedrizzi (1997) afirma que áreas muito extensas pedem uma divisão em partes menores, especialmente no caso de crianças pequenas. Essa divisão torna o ambiente mais aconchegante e evita o desuso de grandes espaços, do qual fala Moore (1996).

Alguns autores afirmam que crianças em ambientes de alta densidade engajam-se em comportamentos passivos e não interacionais, tais como observar, vagar, etc. (Preiser, 1972; Shapiro, 1975, citados em Frost \& cols., 1998)

Mudanças no espaço e no tamanho do grupo também influenciam o comportamento das crianças, como verificou Loo (1972, citado em Frost \& cols., 1999). De um modo geral, em ambientes muito densos, há maior contato físico entre as crianças, o que pode explicar as freqüentes interrupções nas atividades e a maior quantidade de comportamentos agressivos, bem como a menor freqüência de correrias e de comportamentos de atenção, aspectos estes observados pelo autor em ambientes de densidades maiores. 
Peck e Goldman (1978, citados em Frost \& cols., 1999) observaram um contexto pátio e verificaram que um aumento na densidade em uma área de brincadeira estava relacionado a acréscimos de brinquedos imaginativos e à divisão de temas de brincadeiras comuns entre as crianças. Os autores concluíram que um grau maior de exposição aos pares parecia dar às crianças mais oportunidades de partilharem idéias e temas de brincadeiras. Esse estudo também verificou que a densidade parecia ter pouca relação com o brinquedo agressivo e com a agressão física.

Um pátio de escola também precisa oferecer diversidade de espaços e oportunidades para diferentes tipos de brincadeiras, segundo Fedrizzi (1997). Isso atenderá aos diversos interesses das crianças e a seus diferentes níveis de desenvolvimento. Segundo Adams (1990), se o design do pátio não sugere a possibilidade de diversas atividades, é possível que o espaço seja comandado por um determinado grupo ou atividade, em detrimento de outras.

A qualidade do pátio depende da quantidade de brincadeira que ele proporciona, segundo Liempd (1999), isso não precisa ser alcançado somente através da utilização de equipamentos prontos. Materiais comuns, tais como bolas, cordas, sucata, por exemplo, mostraram ser importantes para promover uma grande variedade de jogos e brincadeiras. A variedade nos tipos de solo (areia, grama, ladrilhos) também cria a possibilidade de diferentes tipos de brincadeiras. " $\mathrm{O}$ pátio que possui somente ladrilhos não funciona bem, o pátio somente com grama, também não" (p. 29). Para Liempd, pátios com áreas de atividades variadas e bem definidas proporcionam brincadeiras mais variadas do que pátios sem áreas definidas. As crianças distribuem-se pelo espaço, formam pequenos grupos e os episódios de agressão diminuem. $\mathrm{O}$ autor também afirma que as crianças, em pátios bem definidos e com variedade de opções de atividades, são mais felizes e concentram-se mais.

Liempd (1999) aponta para a importância dos equipamentos que permitem usos diversos. Segundo ele, as crianças raramente brincam com objetos que tenham uma só função. A única exceção parece ser o balanço. As crianças gostam de equipamentos que combinam diferentes atividades, especialmente quando há partes livres que permitem uma mudança de função. Em seu estudo sobre a qualidade de pátios escolares, descreve um composto por árvores, arbustos, um circuito para bicicletas, grama, ladrilhos e um grande galpão com material solto. Esses pátios são pouco dispendiosos em termos financeiros, e a divisão do espaço em áreas de atividades interessantes e o uso de elementos facilmente disponíveis tornam o pátio passível de ser melhor utilizado. Um pátio precisa disponibilizar uma variedade suficiente de materiais e equipamentos, a fim de abarcar a diversidade de interesses e habilidades das crianças. É necessária a criação de zonas, definidas por limites funcionais e visuais, com o intuito de facilitar-se a brincadeira das crianças. Os pátios também devem incluir espaços para atividades passivas e ativas, bem como áreas sociais que permitam atividades em grupos. Pátios nunca estão prontos e acabados, devendo ser constantemente modificados para atender rapidamente às necessidades das crianças.

Visto que os pátios são um ambiente importantíssimo para o desenvolvimento infantil, o presente estudo tem como objetivo ampliar o conhecimento acerca das interações infantis em pátios da escola infantil, além da utilização dos espaços e dos equipamentos dos mesmos. Especificamente, buscase verificar se existem diferenças nas interações das crianças em função da área de pátios da escola infantil e observar a associação dos estados interacionais com os tipos de brinquedos e brincadeiras presentes em cada pátio.

\section{Método}

\section{Participantes}

Foram descritas 1865 interações nos pátios estudados, envolvendo 50 crianças com idades entre 5 e 6 anos. Os dados foram obtidos em duas escolas infantis municipais de Porto Alegre.

A Escola 1 (neste estudo chamada de pátio pequeno) dispõe de 200 metros quadrados de área de pátio e densidade de 5 metros quadrados por criança. Esse pátio caracteriza-se pela presença de uma larga camada de areia grossa e solta em toda a sua extensão, alguns balanços tradicionais, um brinquedo contemporâneo, um palco com arquibancadas de alvenaria e uma churrasqueira.

A Escola 2 (chamada de pátio grande) tem 2010 metros quadrados de área utilizada pelas crianças, além de uma área de aproximadamente 1054 metros quadrados, à qual as crianças não têm acesso, prevista para uma futura horta e pomar, resultando em uma densidade de 40 metros quadrados por criança. Esse pátio está todo gramado, o que normalmente é raro de se verificar nas escolas públicas de Porto Alegre, pois a grama costuma não resistir ao pisoteio intenso das crianças. Há pouca vegetação arbustiva ou árvores. Existe uma caixa de areia e alguns brinquedos tradicionais, como balanços e escorregador. Há, também, um laguinho e um quadro negro fixo na parede. Contra o muro do pátio existe um desnível, no qual as crianças eventualmente sobem.

\section{Delineamento e procedimento}

Em cada escola infantil foram observados os estados interacionais das crianças, utilizando-se a classificação proposta por Parten (1932). Nessas observações, foram levados em conta os tipos de brincadeiras e brinquedos 
utilizados pelas crianças no contexto de dois pátios escolares. Também foram considerados os aspectos físicos presentes em cada um dos pátios (Ex.: equipamentos, área, densidade, etc.). As observações foram realizadas durante o período de brincadeira livre nos pátios, seguindo-se o modelo de observação naturalística.

Em cada escola infantil foram selecionadas duas turmas para a observação. O critério de escolha das crianças observadas foi a idade. Buscou-se observar crianças entre 5 e 6 anos porque estas demonstram uma maior variedade de estados interacionais do que crianças menores. Após um período de familiarização das crianças com os observadores, iniciou-se a coleta de dados, utilizando-se uma câmera VHS e notas de campo. A câmera foi posicionada de forma a obter o maior grau possível de visão do pátio e das crianças. Foram realizadas, ao total, oito sessões de filmagem em cada pátio, com mais ou menos 50 minutos de duração.

\section{Análise dos dados}

Os dados das duas pré-escolas foram analisados separadamente. As sessões de filmagem foram transcritas através do método da amostragem de tempo, utilizando-se janelas de dois minutos. A cada 2 minutos, então, parava-se a fita e se fazia a transcrição de todas as interações que estivessem ocorrendo no momento. Para isso, utilizou-se um protocolo de análise. Esse protocolo era específico para cada pátio. Nele, constavam informações como o tipo de interação, o número de crianças envolvidas, o brinquedo utilizado, a brincadeira desenvolvida, além de um mapa do pátio para a localização mais específica das interações (ver Anexo A).

Os aspectos analisados e suas categorizações foram os seguintes:

1) Estados Interacionais: As interações foram assim descritas, utilizando-se a classificação proposta por Parten (1932):

Desocupado: quando a criança, aparentemente, está "fazendo nada"; geralmente ocupa-se em olhar outras crianças brincando.

Solitário: quando a criança brinca sozinha e independentemente, tomando distância ou não fazendo nenhum esforço de aproximação de outra criança.

Paralelo: quando a criança brinca independentemente, porém com atividades relacionadas às das outras crianças. Não há intenção de influenciar a brincadeira das outras crianças. Elas brincam, então, lado a lado, e não com as outras crianças. Associativo: quando a criança brinca com outras crianças, conversando sobre temas comuns da atividade e trocando brinquedos. Não há subordinação de interesses e cada criança participa do grupo segundo seus interesses e desejos.

Na classificação original de Parten (1932) há, ainda, a categoria Cooperativo, que não foi utilizada neste trabalho por não se terem observado estados interacionais desse tipo. Em relação aos tipos de brinquedos e brincadeiras, não foi utilizada uma classificação a priori. As categorias foram extraídas dos próprios contextos estudados e são assim descritas:

\section{2) Tipos de Brinquedos:}

Equipamentos: aqueles tradicionalmente presentes em pátios e praças: balanço, escorregador, barras, gira-gira, etc.

Areia: incluindo também terra, pedrinhas, pauzinhos, etc. Cantinhos: são aqueles espaços restritos onde as crianças buscam estar sós ou com seus companheiros preferidos. Por exemplo: abrigos na vegetação, buracos oriundos de construções, etc.

Elevacões: envolvem as rampas, escadas, bancos, muros e todos aqueles objetos que permitem que as crianças os utilizem para subir ou escalar (excetuando-se o escorregador). Corpo: envolve a utilização do próprio corpo para brincar: correr, pular, cantar, conversar, lutar, etc.

\section{3) Tipos de Brincadeiras:}

Atividade Física: envolve brincadeiras como correr, subir, andar de balanço, jogar bola, pega-pega, etc.

Construtiva: brincadeiras que envolvem a construção de algo, utilizando-se, por exemplo, de areia, pneus ou objetos em geral.

Simbólica: envolve o faz-de-conta.

Outras: cantar, falar, gritar, etc.

\section{Resultados}

Os resultados foram analisados, utilizando-se a freqüência dos tipos de interação relacionados aos tipos de brinquedos e brincadeiras nos dois pátios.

A partir das freqüências, utilizou-se duas metodologias de análise: Análise de Correspondência (Everitt, 1992) e Análise Logística, utilizando o generalized linear interactive modelling - glim (Healy, 1988; Payne, 1977). A Análise de Correspondência é um método estatístico capaz de identificar a relação entre variáveis categóricas. Os resultados deste método estatístico são gráficos, em geral de duas dimensões, nos quais pode-se visualizar espacialmente as categorias linha e coluna e a relação de proximidade que cada uma das categorias tem entre si. Essa proximidade indica quais categorias linha mais se relacionam com as categorias coluna - quanto mais próximas estão as categorias umas das outras mais associadas elas estão. A Análise Logística, utilizando o generalized linear interactive modelling - glim - complementa a análise de correspondência, pois analisa as variáveis interação e brincadeira separadamente em função do tipo de pátio. Esta análise possibilitou descrever simultaneamente em uma 
projeção bi-dimensional as relações entre as categorias de cada uma das variáveis nominais analisadas. O glim complementa esta análise descritiva permitindo verificar não somente os níveis de significância dos efeitos principais, como também, das interações, considerando as variáveis interação, brincadeira e brinquedo conjuntamente com a variável pátio. Para efeito de descrição dos resultados são apresentados separadamente, envolvendo tipos de brincadeira, tipos de interação e pátio e os tipos de brinquedos igualmente com as variáveis tipo de interação e pátio.

\section{Tipos de Brincadeira, de Interação e Pátio}

Como podemos observar a partir da Tabela 1 , com relação ao estado interacional solitário, as brincadeiras envolvendo atividade física foram as mais freqüentes, tanto no caso do pátio pequeno como no grande $(52,4 \%$ e $26,7 \%$, respectivamente), seguidas da brincadeira construtiva $(3,5 \%$ e 3,9\%, respectivamente). Já, a brincadeira simbólica foi mais freqüente no pátio pequeno $(1,2 \%)$ do que no pátio grande $(0,5 \%)$. Outras brincadeiras, tais como cantar, falar, gritar foram mais freqüentes no pátio pequeno $(3,8 \%)$ do que no pátio grande $(1,0 \%)$. Com relação ao estado interacional associativo, as brincadeiras envolvendo atividade física foram mais freqüentes tanto no pátio pequeno como no pátio grande (16\% e 19,5\%, respectivamente). Já no caso da brincadeira construtiva, as freqüências foram $2,5 \%$ no pátio pequeno e $2,4 \%$ no pátio grande, freqüências bastante próximas, portanto. No caso da brincadeira simbólica, esta se mostrou mais freqüente no pátio grande $(4,8 \%)$ do que no pátio pequeno $(1,6 \%)$. Igualmente, a categoria outras brincadeiras foi mais freqüente no pátio grande $(15,5 \%)$ do que no pátio pequeno (3,9\%). Quanto ao estado interacional paralelo, a brincadeira envolvendo a atividade física foi mais freqüente no pátio pequeno $(9,3 \%)$ do que no pátio grande $(2,1 \%)$. As freqüências da brincadeira construtiva, tanto no pátio pequeno como no pátio grande se mostraram bastante próximas $(1,9 \%$ e $1,8 \%$, respectivamente). No caso das brincadeiras simbólicas pode-se verificar uma freqüência maior no pátio pequeno $(0,6 \%)$ quando comparada ao pátio grande $(0,1 \%)$, revelando-se, neste caso, quase inexistente. Ao contrário, a categoria outras brincadeiras foi mais freqüente no pátio grande $(2,2 \%)$ do que no pátio pequeno $(1,8 \%)$.

A média das freqüências relativas das interações e das brincadeiras envolvendo os dois tipos de pátios pode ser vista na Tabela 2 e na Figura 1 abaixo:

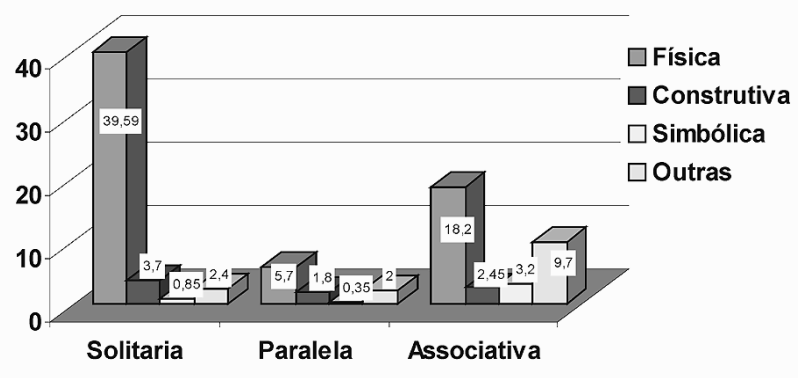

Figura 1. Média das freqüências relativas das variáveis das interações e brincadeiras.

A partir dos dados, relações significativas são encontradas entre Interação tanto com Brincadeira $\left(\chi^{2}=27,63\right.$, g.l. 0,6, $p<0,001)$ como com Pátio $\left(\chi^{2}=14,42\right.$, g.l. 0,2, $\left.p<0,001\right)$, descritas na Tabela 3 . Estes tipos de interações são apresentadas nas Figuras 2 e 3, respectivamente. No entanto, quando analisamos as 3 variáveis juntas (interação, brincadeira

Tabela 1

Freqüencias Relativas das Interações de acordo com o Tipo de Brincadeira nos Pátios Pequeno e Grande

\begin{tabular}{lrccccccc}
\hline & \multicolumn{4}{c}{ Pátio pequeno } & \multicolumn{5}{c}{ Pátio grande } \\
Interação & Física & Construtiva & Simbólica & Outras & Física & Construtiva & Simbólica & Outras \\
\hline Solitária & 52,4 & 3,5 & 1,2 & 3,8 & 26,7 & 3,90 & 0,5 & 1,0 \\
Paralela & 9,3 & 1,9 & 0,6 & 1,8 & 2,1 & 1,80 & 0,1 & 2,2 \\
Associativa & 16,9 & 2,5 & 1,6 & 3,9 & 19,5 & 2,40 & 4,8 & 15,5 \\
& & & & & & &
\end{tabular}

Tabela 2

Média das Freqüências Relativas das Interações e dos Tipos de Brincadeiras

\begin{tabular}{lcccc}
\hline Interação & Física & Construtiva & Simbólica & Outras \\
\hline Solitária & 39,59 & 3,7 & 0,8 & 2,4 \\
Paralela & 5,7 & 1,85 & 0,3 & 2,0 \\
Associativa & 18,2 & 2,5 & 3,2 & 9,7 \\
\hline
\end{tabular}


e pátio) não encontramos diferenças significativas que apontem para uma causalidade entre si. Podemos afirmar que o tamanho do pátio afeta a interação mas não afeta a brincadeira ao passo que a brincadeira, esta sim, é afetada pelo tipo de interação.

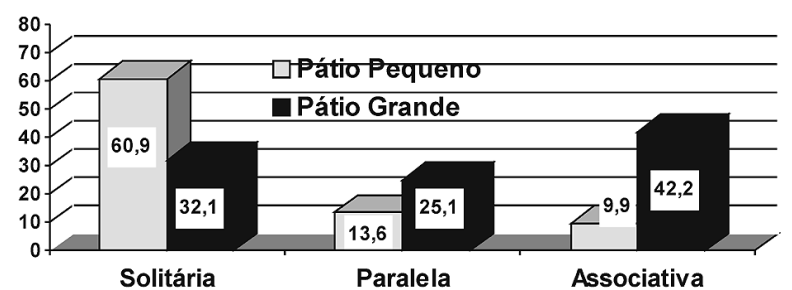

Figura 2. Freqüências relativas envolvendo tipo de interação e pátio.

No caso da associação entre pátio e interação (Figura 2), as diferenças são suficientes para indicar uma relação significativa entre estas duas variáveis

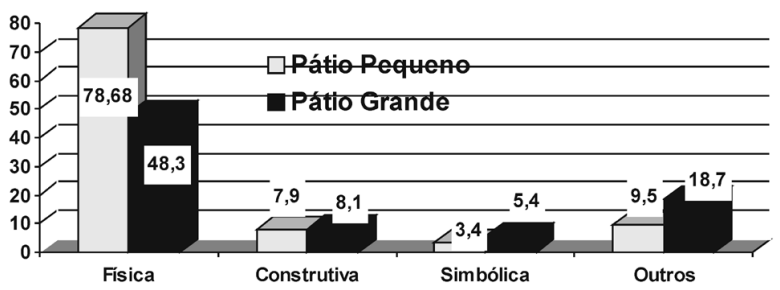

Figura 3. Freqüências relativas envolvendo tipo de brincadeiras e pátio.

As conclusões do glim podem ser observadas nas duas análises de correspondência envolvendo pátio grande (Figura 4) e pátio pequeno (Figura 5). Pode-se verificar que as variáveis brincadeira e interação, nos dois casos, participam de mesmas regiões espaciais representadas nas figuras. Por exemplo, as categorias brincadeira simbólica, outras e tipo de interação associativa estão próximas nos dois tipos de pátio (grande e pequeno). Atividade física e solitária também, da mesma forma (ver elipses). No entanto, pode-se perceber que no caso do pátio pequeno, as brincadeiras e as interações são melhor definidas que no caso do pátio grande. Chamamos de melhor definidas, neste caso, pois cada grupo de associação entre as categorias está eqüidistante um do outro. Em particular, no pátio grande esta definição fica menos clara. Um exemplo disso é a categoria solitário que no caso do pátio grande tem igual relação com atividade física e brincadeira construtiva (ver elipse A). No caso do pátio pequeno, a categoria solitário relaciona-se apenas com atividade física (ver elipse B).

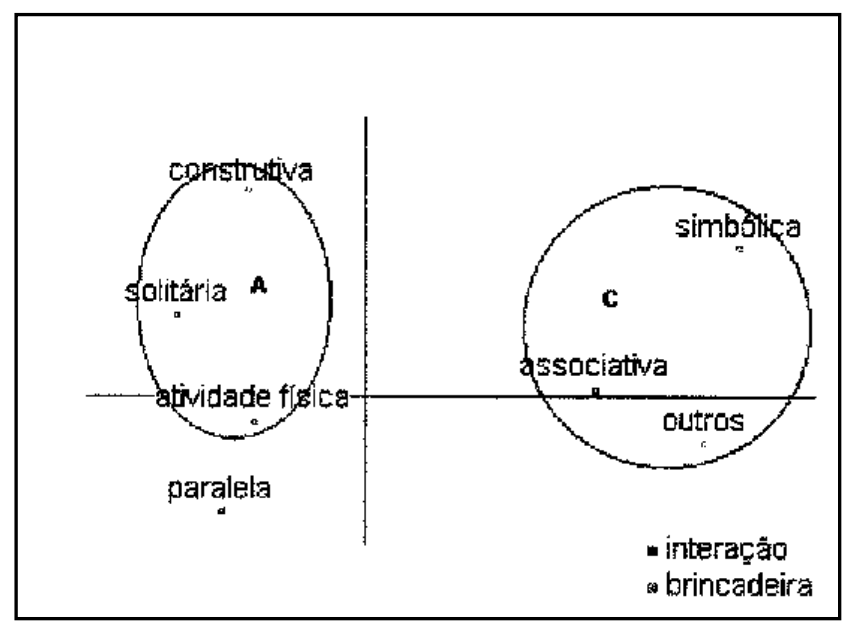

Figura 4. Análise de correspondência entre tipo de brincadeira e interação (Pátio Grande).

Tabela 3

Análise Logistica (GLIM) Considerando as Variáveis Interação, Brincadeira e Pátio

\begin{tabular}{lcccc}
\hline Passos & g.l. & $\begin{array}{c}\text { Desvio } \\
\text { escalar }\end{array}$ & $\begin{array}{c}\text { Mudança } \\
\text { no g.l. }\end{array}$ & $\begin{array}{c}\text { Mudança no } \\
\text { desvio }\end{array}$ \\
\hline "Fit" & 23 & 280,81 & & $-52,82^{* * * * *}$ \\
Interação & 21 & 227,99 & -2 & $-1,99$ \\
Pátio & 20 & 226,00 & -1 & $-175,20 * * * *$ \\
Brincadeira & 17 & 50,84 & -3 & $-14,42^{* * * *}$ \\
Interação x Pátio & 15 & 36,42 & -2 & $-27,63^{* * * *}$ \\
Interação x Brincadeira & 9 & 8,79 & -6 & -4.13 \\
Pátio x Brincadeira & 6 & 4,65 & -3 & -4.65 \\
Interação x Pátio x Brincad. & 0 & 0,00 & -6 & \\
\hline
\end{tabular}

* Significativo a $0,05 * *$ Significativo a $0,02 * * *$ Significativo a $0,01 * * * *$ Significativo a 0,001 


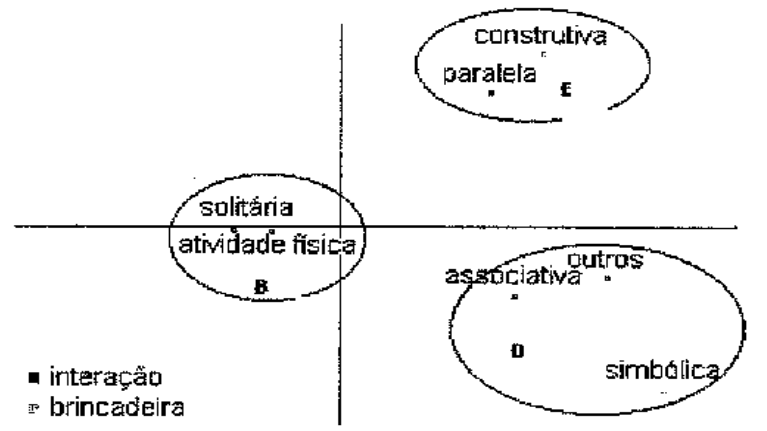

Figura 5. Análise de correspondência entre tipo de brincadeiras e interação (pátio pequeno).

Tipos de Brinquedos, Estados interacionais e Pátios

$\mathrm{Na}$ Tabela 4, apresentam-se as freqüências relativas das interações de acordo com o tipo de brinquedo e pátio. Como podemos verificar, os brinquedos envolvendo equipamentos foram os mais freqüentes nos dois tipos de pátios e nos três tipos de interação. No caso do pátio pequeno, o estado solitário foi mais freqüente utilizando equipamentos $(46,5 \%)$. No pátio grande, esta proporção significa apenas $23,7 \%$, quase metade, portanto. No caso da interação paralela envolvendo equipamentos, o pátio pequeno teve apenas $4,8 \%$, enquanto no pátio grande esta proporção significou $19,9 \%$ dos casos. No tipo de interação associativa, o pátio grande participou com $27,2 \%$ dos casos enquanto o pátio pequeno $17,7 \%$. No caso das elevações, no pátio pequeno $2 \%$ dos casos envolveram o estado solitário, enquanto no pátio grande $4,2 \%$ dos casos de utilização de elevações foram realizadas de forma associativa (contra $0,8 \%$ do pátio pequeno). Os cantinhos só apareceram no pátio pequeno e, na sua maioria, envolveram o estado solitário (5,9\%). A areia, por sua vez, é utilizada na maioria das vezes de forma solitária no pátio pequeno (4,5\%), enquanto que no pátio grande, em ambos, estado solitário e associativo, os casos foram de 5,8\%. A utilização do corpo como brinquedo foi mais frequente na interação associativa no pátio grande $(3,4 \%)$, enquanto que no pátio pequeno, o corpo foi mais freqüentemente utilizado de forma solitária $(3,6 \%)$.

A média das freqüências relativas das interações e dos brinquedos envolvendo os dois tipos de pátio é apresentada na Tabela 5 e na Figura 6.

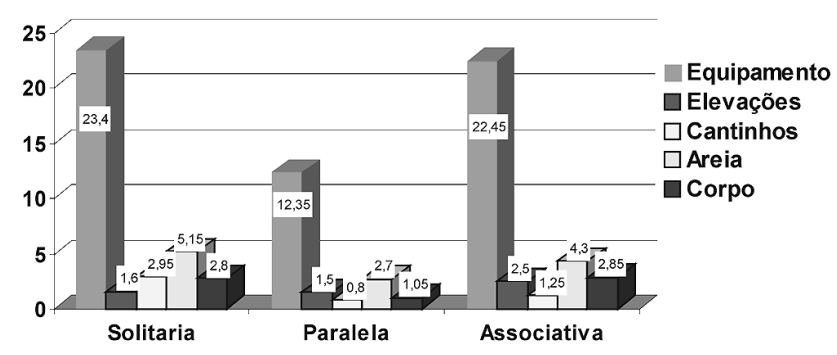

Figura 6. Freqüências das variáveis Interação e Brinquedo.

Tabela 4

Freqüências Relativas das Interações de acordo com o Tipo de Brinquedo nos Pátios Pequeno e Grande

\begin{tabular}{lcccccccccc}
\hline & \multicolumn{1}{c}{ Pátio pequeno } & \multicolumn{6}{c}{ Pátio grande } \\
Interação & $\begin{array}{c}\text { Equipa- } \\
\text { mentos }\end{array}$ & $\begin{array}{c}\text { Eleva- } \\
\text { ções }\end{array}$ & $\begin{array}{c}\text { Canti- } \\
\text { nhos }\end{array}$ & Areia & Corpo & $\begin{array}{c}\text { Equipa- } \\
\text { mentos }\end{array}$ & $\begin{array}{c}\text { Eleva- } \\
\text { ções }\end{array}$ & $\begin{array}{c}\text { Canti- } \\
\text { nhos }\end{array}$ & Areia & Corpo \\
\hline Solitária & 46,5 & 2,0 & 5,9 & 4,5 & 3,6 & 23,7 & 1,2 & 0,0 & 5,8 & 2,0 \\
Paralela & 4,8 & 0,5 & 1,6 & 2,2 & 1,6 & 19,9 & 2,5 & 0,0 & 3,2 & 0,5 \\
Associativa & 17,7 & 0,8 & 2,5 & 2,8 & 2,3 & 27,2 & 4,2 & 0,0 & 5,8 & 3,4 \\
\hline
\end{tabular}

Tabela 5

Médias das Freqüências entre as Variáveis Interação e Tipos de Brinquedo

\begin{tabular}{lccccc}
\hline & Equipamentos & Elevações & Cantinhos & Areia & Corpo \\
\hline Interação & 23,4 & 1,6 & 2,9 & 5,1 & 2,8 \\
Solitária & 12,3 & 1,5 & 0,8 & 2,7 & 1,0 \\
Paralela & 22,4 & 2,5 & 1,2 & 4,3 & 2,85 \\
Associativa & & & & & \\
\hline
\end{tabular}


Para verificar as diferenças apontadas entre as três variáveis Interação (Solitária, Paralela e Associativa), Brinquedo (Equipamentos, Elevações, Cantinhos, Areia e Corpo) e Pátio (Pequeno e Grande) foi computada nova análise logística. Na Tabela 6 , está apresentado o resultado desta análise. Observam-se os efeitos principais significativos das variáveis Interação $\left(\chi^{2}=26,76\right.$, g.l. $\left.0,2, p<0,001\right) \mathrm{e}$ Brinquedo $\left(\chi^{2}=242,70\right.$, g.l. $\left.0,4, p<0,001\right)$. Interações significativas são encontradas entre Pátio tanto com Brinquedos $\left(\chi^{2}=16,02\right.$, g.l. $\left.0,4, p<0,01\right)$ como com Interação $\left(\chi^{2}=19,31\right.$, g.l. $\left.0,2, p<0,001\right)$. A representação gráfica destes tipos de interações é apresentada nas Figuras 7 e 8 , respectivamente. No mesmo caso das brincadeiras, quando analisamos as três variáveis juntas (brinquedos, interação e pátio), não verificamos uma associação significativa que possa indicar uma causalidade entre si. A diferença, neste caso, é que o pátio influencia de forma significativa a interação e o brinquedo, mas o brinquedo não está associado significativamente à interação (no caso anterior, o tipo de brincadeira se relacionava significativamente à interação).

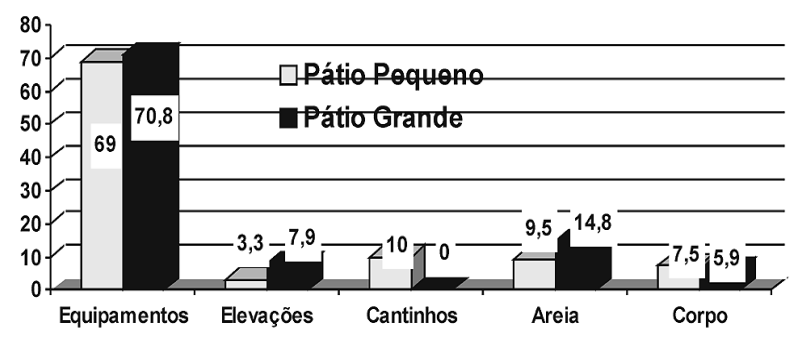

Figura 7. Freqüências relativas envolvendo tipo de brinquedo e pátio.

A partir da Figura 7 pode-se verificar que as diferenças de freqüência de utilização de brinquedos nos diferentes pátios foi suficiente para indicar uma associação entre estas 2 variáveis.

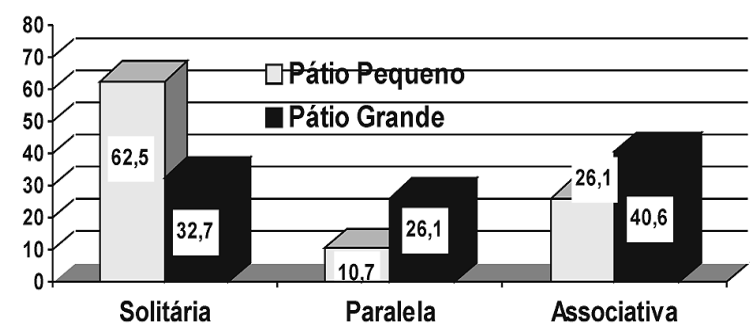

Figura 8. Freqüências relativas envolvendo tipo de interação e pátio.

No caso do tipo de interação e de pátio (Figura 8), as diferenças também mostraram uma associação significativa entre as variáveis, indicando que o pátio pode influenciar o tipo de interação.

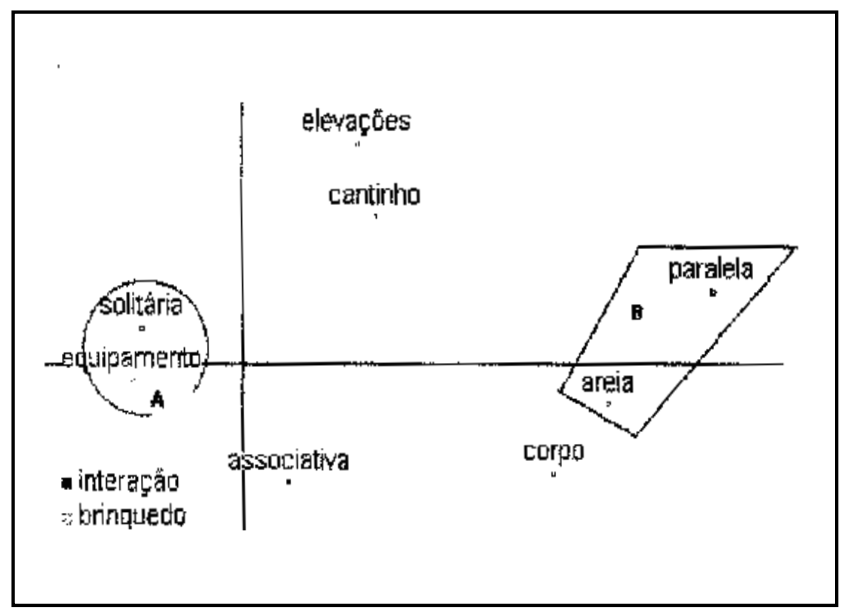

Figura 9. Análise de correspondência entre tipo de brinquedo e interação (pátio pequeno).

Tabela 6

Análise Logística (GLIM) Considerando as Variáveis Interaşão, Brinquedo e Pátio

\begin{tabular}{lcccc}
\hline Passos & g.l. & $\begin{array}{c}\text { Desvio } \\
\text { escalar }\end{array}$ & $\begin{array}{c}\text { Mudança } \\
\text { no g.l. }\end{array}$ & $\begin{array}{c}\text { Mudança no } \\
\text { desvio escalar }\end{array}$ \\
\hline "Fit" & 29 & 313,08 & & $-26,76^{* * * * *}$ \\
Interação & 27 & 286,32 & -2 & $-0,0$ \\
Pátio & 26 & 286,32 & -1 & $-242,70^{* * * *}$ \\
Brincadeira & 22 & 43,63 & -4 & $-19,31^{* * * *}$ \\
Interação x Pátio & 20 & 24,32 & -2 & $-3,39 * * * *$ \\
Interação x Brincadeira & 12 & 20,93 & -8 & $-16,02$ \\
Pátio x Brincadeira & 8 & 4,91 & -4 & $-4,91$ \\
Interação x Pátio x Brincad. & 0 & 0,00 & -8 &
\end{tabular}

$* p<0,05 \quad * * p<0,02 \quad * * * p<0,01 \quad * * * * p<0,005$ 


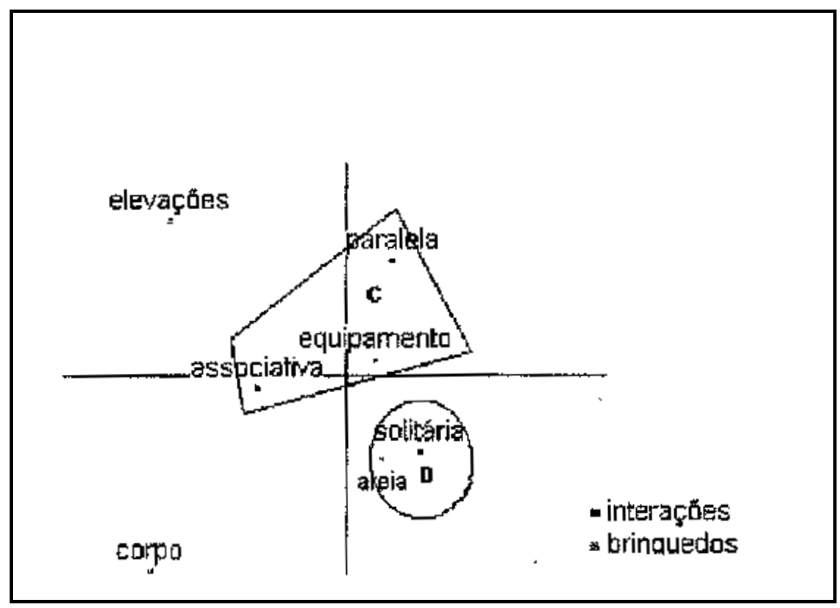

Figura 10. Análise de correspondência entre tipo de brinquedo e interação (pátio grande).

Pode-se observar, a partir da análise de correspondência, que tanto no pátio pequeno (Figura 9) como no grande (Figura 10) há pouca associação entre o tipo de brinquedo e o tipo de interação (também apontada no glim). Pode-se ver, no caso do pátio pequeno uma associação entre equipamento e estado solitário (Elipse A) e interação paralela e areia (Elipse B). Elevações e cantinhos não estiveram associados a nenhum tipo de interação. No pátio grande, a pouca associação também pode ser demonstrada, com ressalvas ao estado solitário e areia (Elipse D). O equipamento, neste caso, está associado tanto com interação associativa como paralela (Elipse C). No caso da associação entre pátio e brinquedos, pode-se dizer que aquele influencia a utilização dos brinquedos visto que eles são usados de maneira diferente em cada tipo de pátio, através de tipos de interações diversas (ver Elipses).

\section{Discussão}

Através dos resultados obtidos nesta pesquisa pode-se concluir que o ambiente escolar, particularmente os pátios, influenciam de maneira importante a interação das crianças. Estudos neste campo permitem, não só conhecer mais as relações que as crianças estabelecem entre si, mas também que professores e arquitetos tenham mais elementos para pensarem os projetos e a utilização destes espaços de maneira a proporcionar um ambiente que favoreça o desenvolvimento da criança em todos os sentidos. A maioria dos autores, ao discutirem acerca da importância dos pátios das escolas infantis para o desenvolvimento das crianças de 0 a 6 anos é unânime em afirmar que eles desempenham um papel fundamental na maneira com que as crianças se relacionam e como interagem. No entanto, embora a maioria partilhe desta opinião, não há total concordância quanto à influência das diferenças físico-espaciais dos pátios das escolas infantis, a saber, área, densidade, brinquedos e equipamentos nas interações das crianças.

Com relação ao tamanho dos pátios, é possível observar que, no pátio pequeno, as interações do tipo solitária (49\%) e desocupada (24\%) foram mais freqüentes do que no pátio grande (solitária: $27 \%$; desocupada: $15 \%$ ). Por outro lado, no pátio grande, as interações do tipo paralela e associativa (57\%) foram mais freqüentes do que no pátio pequeno. Esses resultados mostram que o pátio grande favoreceu o desenvolvimento de interações mais elaboradas entre as crianças, ao contrário do pátio pequeno, onde elas brincaram preferencialmente sozinhas ou mantiveram-se desocupadas. Pode-se levantar algumas hipóteses a respeito destes resultados. A primeira é a de que a maior proximidade entre as crianças, como ocorre no caso de pátios pequenos, não significa maior interação. A segunda é a de que, em ambientes menores, as disputas e conflitos são maiores, o que faz com que as crianças diminuam a freqüência das interações associativas. Muitos autores encontraram dados que corroboram com os resultados deste estudo, como é o caso de Campbell e Dill (1985), Liempd (1999) e Sager (1996). Contrariamente, autores, como Moore (1986), Fedrizzi (1997) e Adams (1990) entendem que pátios muito amplos (portanto com baixa densidade de crianças) colaboram para a diminuição do contato social entre as crianças e para o aumento da quantidade de conflitos e agressões entre elas. Igualmente, uma série de autores como Loo (1972, citado em Frost \& cols., 1999) e Preiser (1972, citado em Frost \& cols., 1999) concordam que a diminuição da área dos pátios e o conseqüente aumento de densidade causam uma série de comportamentos negativos presentes nas interações das crianças. Pode-se pensar que a obtenção de dados controversos entre os autores indica que há poucos resultados conclusivos acerca do melhor modelo de pátio que possa conduzir a interações mais qualificadas entre crianças. Indicações provenientes de estudos acerca do arranjo espacial (Legendre, 1995) e da definição espacial (Moore, 1986) podem contribuir para explicar o porquê da diversidade de tipos de interação apresentados pelas crianças nesses ambientes.

No caso da relação entre tipo de brinquedo e interação, no pátio grande houve pouca associação entre esses dois aspectos. A utilização dos equipamentos, por exemplo, não esteve relacionada a um estado interacional em especial. Do mesmo modo, a utilização do corpo como brinquedo e o uso das elevações não se relacionaram a um tipo específico de interação. A única categoria que mostrou associação específica foi a utilização da areia, que relacionou-se ao estado solitário. Já no pátio pequeno, os equipamentos relacionaram-se a atividades solitárias e as interações 
associativas e paralelas não se mostraram especificamente relacionadas ao tipo de brinquedo. Estes resultados parecem confirmar as conclusões de Vanderberg (1981) que afirma que ambientes providos de equipamentos que proporcionam atividades motoras amplas aumentam o nível de interação das crianças. Em resumo, neste estudo, os resultados indicam que no pátio grande as crianças estabeleceram interações mais variadas e fluídas com relação aos aspectos ambientais presentes nesse contexto.

No caso das brincadeiras relacionadas ao tipo de interação, houve forte associação, principalmente, no pátio pequeno. Estiveram relacionados: brincadeiras que envolviam atividade física com estado solitário, brincadeiras construtivas com interações paralelas e outras brincadeiras - como falar, cantar, gritar - e simbólicas com interações associativas. No pátio grande, ao contrário, as categorias mostraram pouca associação entre si, o que demonstra que o tipo de brincadeira ocorre independentemente dos tipos de interação nesse pátio. Aqui, novamente, verifica-se que no pátio grande as crianças estabeleceram interações mais fluídas com relação aos aspectos ambientais do contexto.

Conclui-se que o pátio grande favoreceu o estabelecimento de interações mais variadas entre as crianças e permitiu uma maior fluidez de suas interações em relação ao ambiente físico.

Sabe-se, igualmente, que muitos outros fatores podem estar envolvidos nos processos de interação das crianças e que não foram abordados neste estudo. Estes fatores dizem respeito à proposta pedagógica, ao estilo do professor, a aspectos culturais de cada região ou país, e muitos outros. Além disso, os resultados obtidos devem ser também relativizados do ponto de vista da amostra desta pesquisa, já que se investigou apenas duas escolas do ensino infantil municipal de Porto Alegre.

Estudos deste tipo não têm como objetivo principal indicar modelos ideais de pátios de escola infantil (outras variáveis deveriam ser estudadas para poder fazê-lo). No entanto, o conhecimento que se obtém da interação das crianças nestes contextos pode servir de parâmetro para otimizar os espaços da escola infantil, de forma que eles possam propiciar diferentes tipos de interação e desafios para as crianças que deles usufruem.

\section{Referências}

Adams, E. (1990). Learning through landscapes. Learning Through Landscapes Trust: Winchester.

Barker, R. G. (1965). Exploration in ecological psychology. American Psychologist, 20,1-14.

Campbell, S. D. \& Dill, N. (1985). The impact of changes in spatial density on children's behaviour in day care settings. Em J. L. Frost \& S. Sunderlin (Orgs.), When children play (pp. 113-137). Wheaton, MD: Association for Childhood Educational International.

Campbell, S. D. \& Frost, J. L. (1985). The effects of playground type on cognitive and social play behavior of grade two children. Em J. L. Frost \& S. Sunderlin (Orgs.), When children play (pp. 88-107). Wheaton, MD: Association for Childhood Educational International.

Campos-de-Carvalho, M. I. \& Ferreira,-R. (1993). Psicologia ambiental: Algumas considerações. Psicologia: Teoria e Pesquisa, 9, 435-447.

Civiletti, M. V. P. (1992). Modalidade do objeto e interação social de pares de 24 a 36 meses. Subsídio para uma proposta educacional na creche. Tese de Doutorado nãopublicada, Universidade Federal do Rio de Janeiro. Rio de Janeiro, RJ.

Everitt, B. S. (1992). The analysis of contingency tables. London: Chapman \& Hall.

Fedrizzi, B. (1997). Improving public schoolyards in Porto Alegre, Brazil. Tese de Doutorado, Swedish University of Agricultural Sciences. Alnarp, Suécia.

Frost, J. L. (1989). Play environment for young children in the USA: 1880-1990. Children's Environments Quarterly, 6(4), 17-24.

Frost, J. L., Shin, D. \& Jacobs, P. J. (1999). Physical environments and children's play. Em O. N. Saracho \& B. Spodek (Orgs.), Multiple perspectives on play in early childhood education (pp. 255-294). Albany: State University of New York.

Hart, C. \& Sheenan, R. (1986). Preschoolers' play behavior in outdoor environments: Effects of traditional and contemporary playgrounds. American Educational Research Journal, 23, 668-678.

Healy, M. J. R. (1988). GLIM: An introduction. Oxford: Clarendon Press.

Ladd, C. W. \& Coleman, C. C. (1992). Young children's peer relationship: Form, features, and functions. (Manuscrito não-publicado)

Legendre, A. (1995). The effects of environmentally modulated visual accessibility to caregivers on early peer interactions. International Journal of Behavioral Development,18, 297-313.

Lewin, K. (1951). Field theory in social science. Harper: New York.

Liempd, I. V. (1999). Playgrounds of childcare centers: How to determine their quality? Bulletin of People-Environment Studies, 13, 29-32.

Moore, G. T. (1986). Effects of the spatial definition of behavior settings on children's behavior: A quasi-experimental field study. Journal of Environmental Psychology, 6, 205-231.

Neill, S. R. \& Denham, E. J. M. (1982). The effects of preschool building design. Educational Research, 24, 107-111.

Parten, M. B. (1932). Social participation among preschool children. Journal of Abnormal and Social Pychology, 27, 243-269.

Payne, C. (1997). The log-linear model for contingency tables. Em C. A. O'Muirchearthaig \& C. Payne (Orgs.), The analiysis of survey data (pp. 123-178). Chichester: Wiley.

Sager, F. (1996). O brincar e os conflitos entre as crianças. Dissertação de Mestrado não-publicada, Curso de Pós-graduação em Psicologia do Desenvolvimento, Universidade Federal do Rio Grande do Sul. Porto Alegre, RS.

Smith, P. K. \& Conolly, K. J. (1980). The ecology of preschool behavior. Cambridge: University Press.

Vanderberg, B. (1981). Developmental features of children's play with objects. The Journal of Psychology, 109, 27-29.

Sobre os autores

Fabio Sager é Doutor em Psicologia do Desenvolvimento pela Universidade Federal do Rio Grande do Sul.

Tania Mara Sperb é Professora do Curso de Pós-graduação em Psicologia do Desenvolvimento na Universidade Federal do Rio Grande do Sul.

Antonio Roazzi é Professor Adjunto da Universidade Federal de Pernambuco.

Fernanda Marques Martins é Bolsista PIBIC/UFRGS. 
ANEXO A

\section{PROTOCOLO DESCRITIVO DAS OBSERVAÇÕES - PÁTIO 1}

Data:

Escola:

Tabela 1

Descrição do Tipo de Interação, Tipo de Brinquedo e Brincadeira

\begin{tabular}{|l|l|}
\hline INTERAÇÃO & BRINQUEDO \\
\hline \\
\hline \\
\hline \\
\hline \\
\hline
\end{tabular}

PLANTA BAIXA - PÁTIO 1 (área 200 m²)

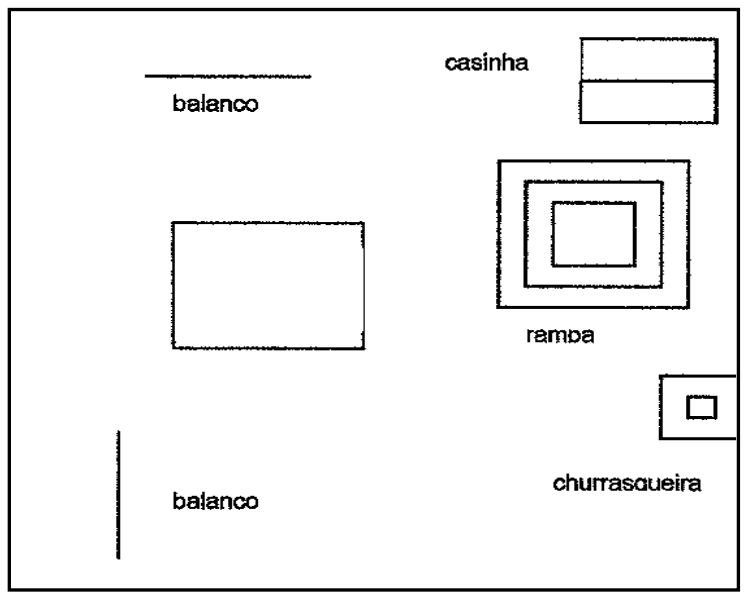

Obs: a planta não está em escala. 


\section{PROTOCOLO DESCRITIVO DAS OBSERVAÇÕES - PÁTIO 2}

Data:

Escola:

Tabela 2

Descrição do Tipo de Interação, Tipo de Brinquedo e Brincadeira

\begin{tabular}{|l|l|}
\hline INTERAÇÃO & BRINQUEDO \\
\hline \\
\hline \\
\hline \\
\hline \\
\hline
\end{tabular}

PLANTA BAIXA - PÁTIO 2 (área 2010 m²)

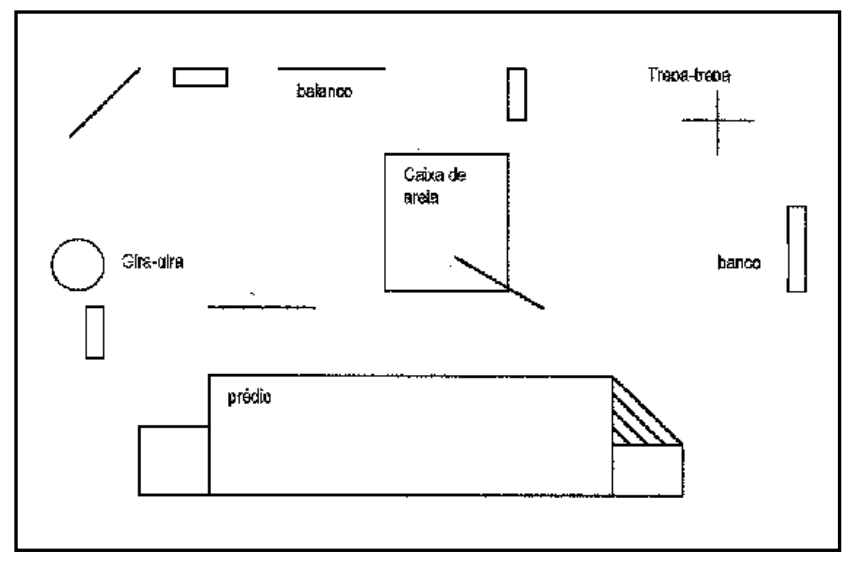

Obs: a planta não está em escala 


\section{PISAD}

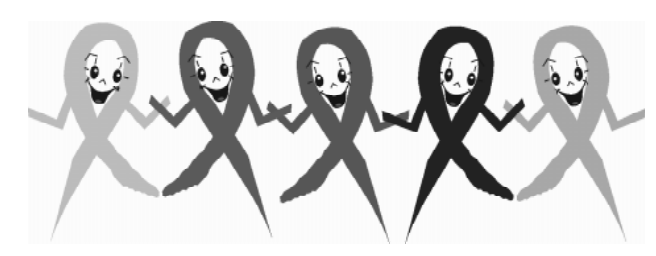

\section{PROGRAMA DE INTERVENÇÃO EM SEXUALIDADE, AGRESSIVIDADE, AIDS E DROGAS}

Fundado em maio de 1997, é um programa de intervenção e capacitação relacionado a Sexualidade, Agressividade, AIDS e Drogas. O programa é vinculado ao Centro de Estudos Psicológicos sobre Meninos e Meninas de Rua - CEP-RUA - da Universidade Federal do Rio Grande do Sul.

RUA RAMIRO BARCELOS, 2600/104 90035-003 PORTO ALEGRE/RS

FONE: (51) 33165150 